\title{
ASSESSMENT OF THE AGE OF MAJORITY USING DEMIRJIAN MINERALIZATION STAGES AMONG A SAMPLE OF THE EGYPTIAN POPULATION
}

\author{
Walaa Samir * and Fatma Mohamed Hassan **
}

\begin{abstract}
Background and objectives: Determination of the age of majority is a major problem in forensics. This study aimed to evaluate the usefulness of Demirjian's stages of teeth development in estimating the age of majority from the left mandibular molar among a sample of the Egyptian population
\end{abstract}

Methods: A prospective cross-sectional study included a sample of 134 digital panoramic radiographs of participants aged 15-26 years. The left lower third molars were analyzed using Navegatium DICOM viewer software for the medical sector. e version 1.10.0.0 applicable on Microsoft. The effectiveness of Demirjian's stages was assessed by using accuracy, sensitivity, specificity, positive (LR+) and negative (LR-) likelihood ratios, and positive and negative predictive values

Results: The test showed better specificity for stage H $(90.91 \%$ for males, and $63.64 \%$ for females), and better sensitivity for stage G (98\% for males, and $95.16 \%$ for females) for adult age. The accuracy of the test was $(85.25 \%$ for males and $72.60 \%$ for females) in stage $\mathrm{H}$, and $(93.44 \%$ for males and $87.67 \%$ for females) in stage $\mathrm{G}$.

Conclusion: Demirjian's stages $\mathrm{G}$ and $\mathrm{H}$ are fairly reliable method for estimating the age of majority among Egyptians.

KEY WORDS: Age of majority; Demirjian's stages; Egyptians; Left mandibular third molar.

\section{INTRODUCTION}

In forensic practice, determination of the majority age of individuals is a pivotal issue (Lizarbe et al. 2017). The majority age represented when a person has considered an adult, having all rights and adulthood responsibilities. This age varies between different jurisdictions (www.parentcenterhub.org/ age-of-majority/).

In Egypt, the majority age is eighteen years , it represents a critical cut-off age; the minimum legal marriage age for males and females, age of consent

\footnotetext{
* Lecturer of oral maxillofacial radiology, Faculty of Dentistry, Bani-sauf University

** Lecturer of forensic medicine and clinical toxicology, Faculty of Medicine, Cairo University
} 
(https://www.ageofconsent.net/world/egypt), driving license (http://www.adcidl.com/Drivingin-Egypt.html) and voting in elections (http://www. egypttoday.com/Article/2/39736/Overview-ofvoting-rights-in-Egypt).

The Study Group on Forensic Age Diagnostics (AGFAD) recommendations for determining the age of criminal responsibility included physical and dental examination together with an X-ray examination of the left hand (Schmeling et al. 2008).

The third molars represent the only teeth still in development in adolescents and young adults whose dental maturation has almost complete (Lizarbe et al. 2017), and also the most common visible teeth from crypt appearance to apex completion on children and young adults' radiographs (Sharma et al. 2017).

In 1973, a new classification of tooth mineralization stages was released by Demirjian at al (Demirjian et al. 1973). Mincer et al. were the first to use Demirjian's mineralization stages to assess the third molars reliability in distinguishing adults from minors in 823 Americans. Their results showed that $90 \%$ of males and $92 \%$ of females with third molars in Demirjian's stage H were more than 18 years old (Mincer at al. 1993). In 2014, Costa et al. used the $\mathrm{G}$ and $\mathrm{H}$ developmental stages of Demirjian to determine the adult age among Mexicans and Columbians (Costa et al. 2014).

Currently, there is no evidence of the usefulness of Demirjian mineralization stages in estimating the majority age among Egyptians. Therefore the aim of this study was to detect the usefulness of the root development stages of Demirjian in discriminating adults and minors among a sample of the Egyptian population.

\section{MATERIALS AND METHODS}

\section{Study population}

The sample consisted of 134 (73 females and 61 males) digital panoramic radiographs
(OPTs) of patients aged between 15 and 26 years. The inclusion criteria included subjects with known age and erupted of the left mandibular third molars. Exclusion criteria included panoramic radiographs of patients with systemic diseases, dental abnormalities, patients with presenting orthodontic appliances, or absence of left mandibular TMs either may be congenital or by extraction. Data about sex, date of birth and date of radiographs were collected for each patient.

\section{Ethical considerations}

The study was conducted according to the declaration of Helsinki and the protocol was approved by the Ethics Research Board of Beni-suef oral and maxillofacial radiology department (World Medical Association, 2001). Written informed consents were obtained from the adults and guardians of the minors before the enrollment in study.

\section{Measurements}

The discrimination of adults and minors was studied using Demirjian's stages of dental maturity (Demirjian et al. 1973), D to H stages were used as cut-offs points to estimate adulthood.

The left mandibular third molar of each individual was analyzed using Navegatium DICOM viewer software for the medical sector. e version 1.10.0.0 applicable on Microsoft .

\section{Statistical analysis}

Data were coded and entered using the statistical package SPSS (Statistical Package for the Social Sciences) version 25. Data was summarized using mean, standard deviation, median, minimum and maximum in quantitative data and using frequency (count) and relative frequency (percentage) for categorical data. Standard diagnostic indices including sensitivity, specificity, positive predictive value (PPV), negative predictive value (NPV) and diagnostic efficacy were calculated as described 


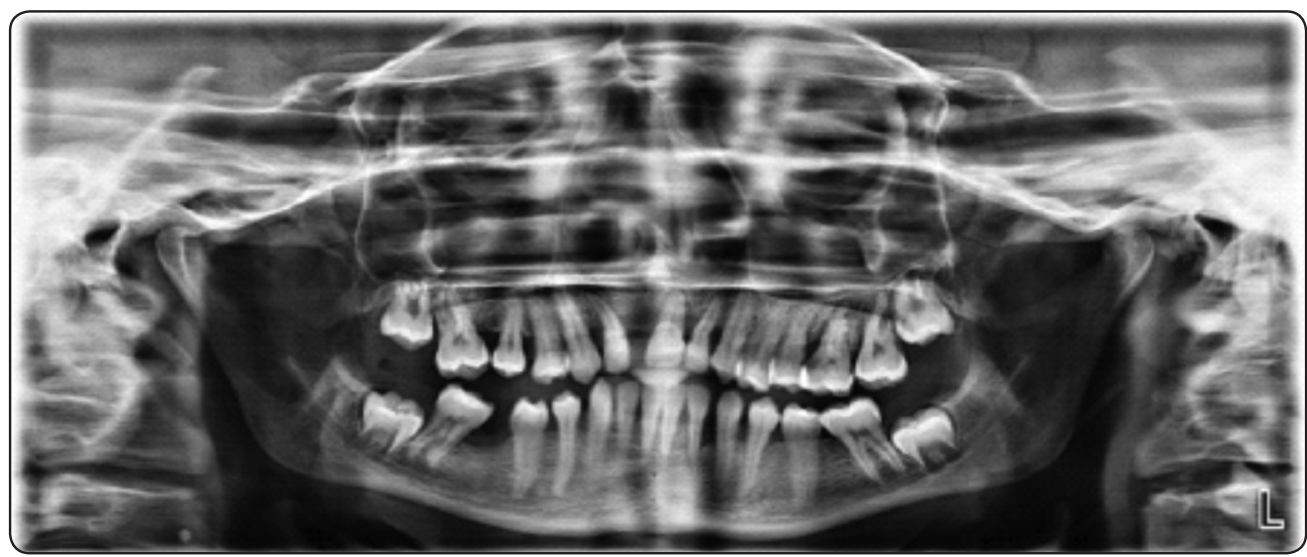

Fig. (1) Capture for E stage image for 19 years old female patient.

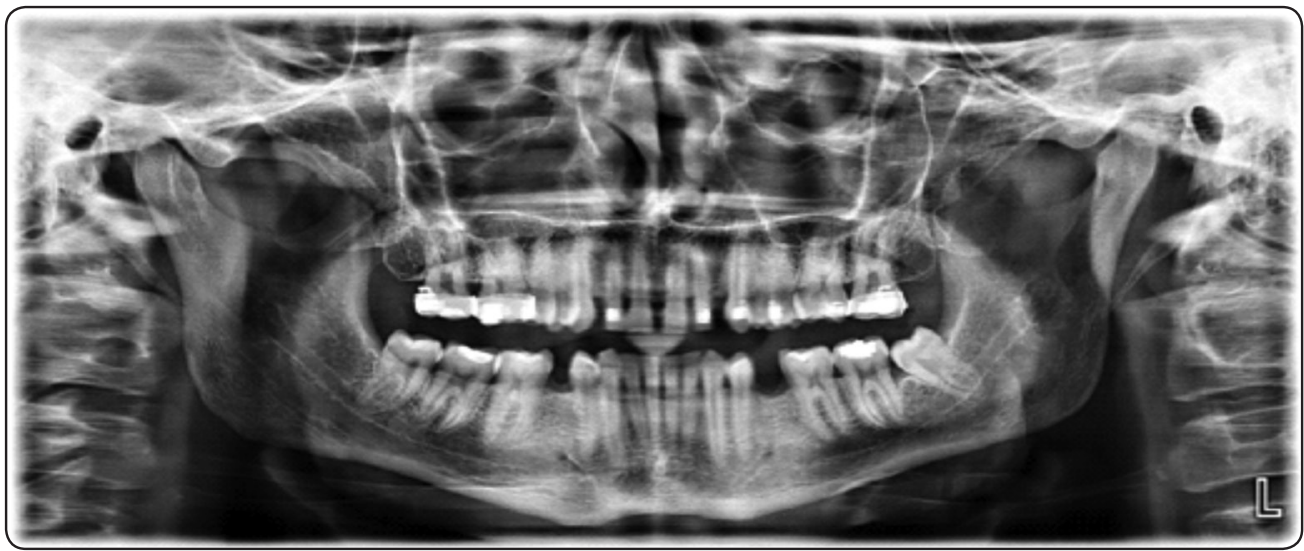

Fig. (2) Capture for $\mathrm{H}$ stage image for 20 years old male old patient.

by (Galen, 1980). ROC curve was constructed with area under curve analysis performed to detect overall effectiveness of Demirjian's stages in detection of adults. The value of the area under the ROC curve shows the accuracy of the test or how well the test identify adults from minors. An area of 1 represents a perfect test, while an area of 0.5 represents a worthless test (Fletcher and Fletcher, 2005). Comparisons between quantitative variables were done using the non-parametric Mann-Whitney test (Chan, 2003). P value less than 0.05 was considered as statistically significant.

\section{Equations}

Positive likelihood ratio $($ PLR $)=$ sensitivity/ (1-specificity)

Negative likelihood ratio $(N L R)=(1$-sensitivity $)$ /specificity

Positive post-test probability $=P P V$

\section{RESULTS}

Table 1 shows the distribution of age and sex among the studied sample of OPTs. Figure 3 illustrates the age distribution across Demirjian stages. No differences in age between sexes across all Demirjian stages (Table 2). Table 3 shows the distribution of subjects who are 18 years or older by Demirjian stages and sex. Table 4 shows the performance of the cut-off values of Demirjian stages for males and females separately by 2 -by- 2 contingency tables. The values of the area under the ROC curve for discriminating between adults and minors were 0.779 (95\%CI, 0.669 to 0.890 ) for stage $\mathrm{H}$, followed by 0.778 (95\%CI, 0.647 to 0.908 ) for stage $\mathrm{G}$ and 0.718 (95\%CI, 0.578 to 0.858$)$ for stage F (Figure 4). Table (5) shows that among the tested Demirjian's stages, stage H showed the best specificity; $90.91 \%$ and $63.64 \%$ in males and females, respectively. The sensitivity of the test in males was $98 \%, 98 \%$, and $84 \%$ for stage $\mathrm{F}, \mathrm{G}$ and $\mathrm{H}$ respectively, and in females was $98.39 \%, 95.16 \%$, and $74.19 \%$ for stage $\mathrm{F}, \mathrm{G}$, and $\mathrm{H}$ respectively. 
TABLE (1) Distribution of age and sex among the studied Egyptian sample of panoramic radiographs

\begin{tabular}{|c|c|c|c|c|}
\hline \multicolumn{2}{|c|}{} & \multicolumn{3}{c|}{ Sex } \\
\cline { 3 - 5 } \multicolumn{2}{c|}{} & Females & Males & Total \\
\cline { 2 - 5 } \multicolumn{1}{c|}{} & Count & Count & Count \\
\hline \multirow{4}{*}{ Age } & 15 & 0 & 3 & 3 \\
\cline { 2 - 5 } & 16 & 5 & 7 & 12 \\
\cline { 2 - 5 } & 17 & 6 & 1 & 7 \\
\cline { 2 - 5 } & 18 & 4 & 2 & 6 \\
\cline { 2 - 5 } & 19 & 6 & 12 & 18 \\
\cline { 2 - 5 } & 20 & 9 & 8 & 17 \\
\cline { 2 - 5 } & 21 & 1 & 6 & 7 \\
\cline { 2 - 5 } & 22 & 16 & 9 & 25 \\
\cline { 2 - 5 } & 23 & 15 & 2 & 17 \\
\cline { 2 - 5 } & 24 & 6 & 1 & 7 \\
\cline { 2 - 5 } & 25 & 5 & 6 & 11 \\
\cline { 2 - 5 } & 26 & 0 & 4 & 4 \\
\cline { 2 - 5 } & Total & 73 & 61 & 134 \\
\hline
\end{tabular}

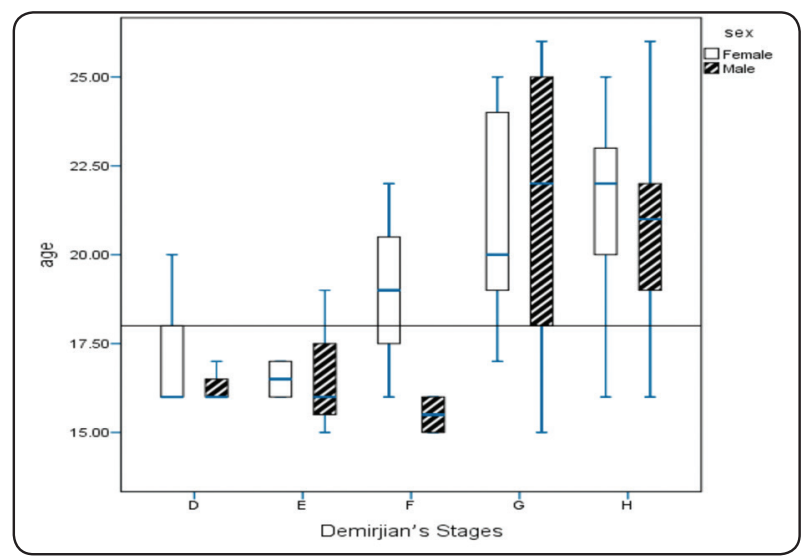

Fig. (3) Box-plot of the relationship between age and Demirjian's stages of the left mandibular third molar. The box-plots show median and inter-quartile ranges, lines extending from the box show maximum and minimum ages

TABLE (2) Summary statistics of the age (years) in relation to Demirjian's stages (D-H) of lower left third molar among Egyptian males and females

\begin{tabular}{|c|c|c|c|c|c|c|c|c|c|c|c|c|c|c|}
\hline & \multicolumn{6}{|c|}{ Female age } & \multicolumn{6}{|c|}{ Male age } & \multirow[b]{2}{*}{$P$ value } \\
\hline & & $\mathrm{N}$ & Mean & SD & Median & $\begin{array}{c}\text { 1st } \\
\text { quartile }\end{array}$ & $\begin{array}{c}\text { 3rd } \\
\text { quartile }\end{array}$ & $\mathrm{N}$ & Mean & $\mathrm{SD}$ & Median & $\begin{array}{c}\text { 1st } \\
\text { quartile }\end{array}$ & $\begin{array}{c}\text { 3rd } \\
\text { quartile }\end{array}$ & \\
\hline \multirow{5}{*}{$\begin{array}{c}\text { Demirjian's } \\
\text { Stages }\end{array}$} & $\mathrm{D}$ & 3 & 17.33 & 2.31 & 16.00 & 16.00 & 20.00 & 4 & 16.25 & 0.50 & 16.00 & 16.00 & 16.50 & 0.857 \\
\hline & E & 2 & 16.50 & 0.71 & 16.50 & 16.00 & 17.00 & 3 & 16.67 & 2.08 & 16.00 & 15.00 & 19.00 & 0.800 \\
\hline & $\mathrm{F}$ & 3 & 19.00 & 3.00 & 19.00 & 16.00 & 22.00 & 2 & 15.50 & 0.71 & 15.50 & 15.00 & 16.00 & 0.200 \\
\hline & $\mathrm{G}$ & 15 & 21.27 & 2.99 & 20.00 & 18.00 & 24.00 & 9 & 21.11 & 4.20 & 22.00 & 18.00 & 25.00 & 0.953 \\
\hline & $\mathrm{H}$ & 50 & 21.48 & 2.22 & 22.00 & 20.00 & 23.00 & 43 & 21.16 & 2.37 & 21.00 & 19.00 & 22.00 & 0.161 \\
\hline
\end{tabular}

TABLE (3) The distribution of the subjects of 18 years and older within Demirjian stage in Egyptian males and females

\begin{tabular}{|c|c|c|c|}
\hline \multicolumn{2}{|c|}{} & Females & Males \\
\cline { 2 - 4 } \multicolumn{2}{|c|}{} & Age $>=18$ & age $>=18$ \\
\cline { 2 - 4 } & $\mathrm{N}$ & 1 & $\mathrm{~N}$ \\
\hline \multirow{4}{*}{ Demirjian's Stages } & $\mathrm{F}$ & 0 & 0 \\
\cline { 2 - 4 } & $\mathrm{F}$ & 2 & 1 \\
\cline { 2 - 4 } & $\mathrm{G}$ & 13 & 0 \\
\cline { 2 - 4 } & $\mathrm{H}$ & 46 & 7 \\
\hline
\end{tabular}

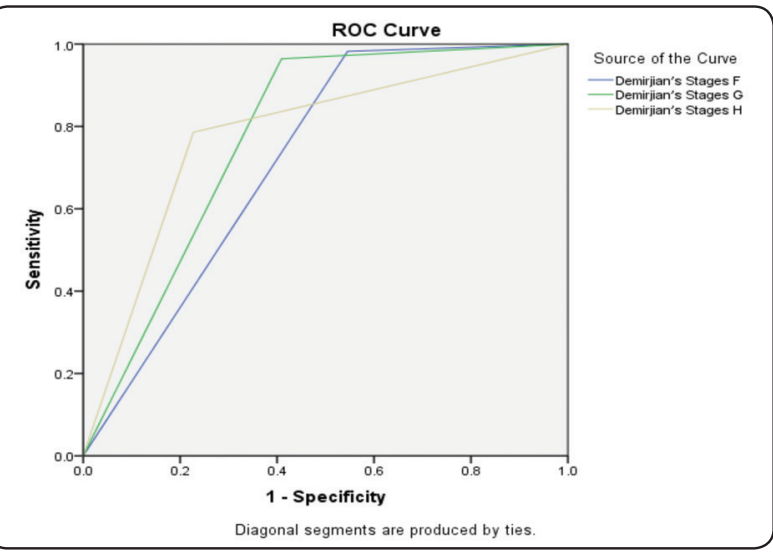

Fig. (4) Receiver operating characteristic (ROC) curve for Demirjian stages $\mathrm{F}$ to $\mathrm{H}$ of the lower left third molar for discriminating adults and minors in Egyptians. 
TABLE (4) 2-by-2 Contingency table discriminating the performance of the test on being adult or minor for Demirjian's stages F to H in Egyptian males and females

\begin{tabular}{|c|c|c|c|c|c|c|c|}
\hline & \multicolumn{6}{|c|}{ Sex } \\
\hline & & \multicolumn{3}{|c|}{ Female } & \multicolumn{3}{|c|}{ Male } \\
\hline & & \multicolumn{3}{|c|}{ age groups } & \multicolumn{3}{|c|}{ age groups } \\
\hline & & $>=18$ & $<18$ & Total & $>=18$ & $<18$ & Total \\
\hline & & Count & Count & Count & Count & Count & Count \\
\hline \multirow{2}{*}{ Demirjian's Stages F } & $>=F$ & 61 & 7 & 68 & 49 & 5 & 54 \\
\hline & $<\mathrm{F}$ & 1 & 4 & 5 & 1 & 6 & 7 \\
\hline \multirow{2}{*}{ Demirjian's Stages G } & $>=\mathrm{G}$ & 59 & 6 & 65 & 49 & 3 & 52 \\
\hline & $<\mathrm{G}$ & 3 & 5 & 8 & 1 & 8 & 9 \\
\hline \multirow{3}{*}{ Demirjian's Stages H } & $>=\mathrm{H}$ & 46 & 4 & 50 & 42 & 1 & 43 \\
\hline & $<\mathrm{H}$ & 16 & 7 & 23 & 8 & 10 & 18 \\
\hline & Total & 62 & 11 & 73 & 50 & 11 & 61 \\
\hline
\end{tabular}

TABLE (5) Percentage of sensitivity, specificity, accuracy, and post-test probability (95\% confidence interval) for Demirjian's stages F to H of the lower left third molar to test the age of majority in Egyptian males and females,

\begin{tabular}{|c|c|c|c|c|}
\hline & & Stage F & Stage G & Stage $\mathrm{H}$ \\
\hline \multirow[t]{7}{*}{ Males } & Sensitivity & $\begin{array}{l}98.00 \% \\
(89.35 \% \text { to } 99.95 \%)\end{array}$ & $\begin{array}{l}98.00 \% \\
(89.35 \% \text { to } 99.95 \%)\end{array}$ & $\begin{array}{l}84.00 \% \\
(70.89 \% \text { to } 92.83 \%)\end{array}$ \\
\hline & Specificity & $\begin{array}{l}54.55 \% \\
(23.38 \% \text { to } 83.25 \%)\end{array}$ & $\begin{array}{l}72.73 \% \\
(39.03 \% \text { to } 93.98 \%)\end{array}$ & $\begin{array}{l}90.91 \% \\
(58.72 \% \text { to } 99.77 \%)\end{array}$ \\
\hline & Positive Likelihood Ratio & $2.16(1.13$ to 4.12$)$ & 3.59 (1.37 to 9.44$)$ & $9.24(1.42$ to 60.11$)$ \\
\hline & Negative Likelihood Ratio & $0.04(0.00$ to 0.27$)$ & $0.03(0.00$ to 0.20$)$ & $0.18(0.09$ to 0.34$)$ \\
\hline & Positive Predictive Value & $\begin{array}{l}90.74 \% \\
(83.67 \% \text { to } 94.94 \%)\end{array}$ & $\begin{array}{l}94.23 \% \\
(86.14 \% \text { to } 97.72 \%)\end{array}$ & $\begin{array}{l}97.67 \% \\
(86.59 \% \text { to } 99.64 \%)\end{array}$ \\
\hline & Negative Predictive Value & $\begin{array}{l}85.71 \% \\
(44.47 \% \text { to } 97.82 \%)\end{array}$ & $\begin{array}{l}88.89 \% \\
(52.64 \% \text { to } 98.29 \%)\end{array}$ & $\begin{array}{l}55.56 \% \\
(39.20 \% \text { to } 70.79 \%)\end{array}$ \\
\hline & Accuracy & $\begin{array}{l}90.16 \% \\
(79.81 \% \text { to } 96.30 \%)\end{array}$ & $\begin{array}{l}93.44 \% \\
(84.05 \% \text { to } 98.18 \%)\end{array}$ & $\begin{array}{l}85.25 \% \\
(73.83 \% \text { to } 93.02 \%)\end{array}$ \\
\hline \multirow[t]{7}{*}{ Females } & Sensitivity & $\begin{array}{l}98.39 \% \\
(91.34 \% \text { to } 99.96 \%)\end{array}$ & $\begin{array}{l}95.16 \% \\
(86.50 \% \text { to } 98.99 \%)\end{array}$ & $\begin{array}{l}74.19 \% \\
(61.50 \% \text { to } 84.47 \%)\end{array}$ \\
\hline & Specificity & $\begin{array}{l}36.36 \% \\
(10.93 \% \text { to } 69.21 \%)\end{array}$ & $\begin{array}{l}45.45 \% \\
(16.75 \% \text { to } 76.62 \%)\end{array}$ & $\begin{array}{l}63.64 \% \\
(30.79 \% \text { to } 89.07 \%)\end{array}$ \\
\hline & Positive Likelihood Ratio & $1.55(0.99$ to 2.42$)$ & $1.74(1.01$ to 3.00$)$ & $2.04(0.92$ to 4.52$)$ \\
\hline & Negative Likelihood Ratio & $0.04(0.01$ to 0.36$)$ & $0.11(0.03$ to 0.38$)$ & $0.41(0.22$ to 0.75$)$ \\
\hline & Positive Predictive Value & $\begin{array}{l}89.71 \% \\
(84.78 \% \text { to } 93.17 \%)\end{array}$ & $\begin{array}{l}90.77 \% \\
(85.11 \% \text { to } 94.42 \%)\end{array}$ & $\begin{array}{l}92.00 \% \\
(83.85 \% \text { to } 96.22 \%)\end{array}$ \\
\hline & Negative Predictive Value & $\begin{array}{l}80.00 \% \\
(32.98 \% \text { to } 97.02 \%)\end{array}$ & $\begin{array}{l}62.50 \% \\
(31.67 \% \text { to } 85.70 \%)\end{array}$ & $\begin{array}{l}30.43 \% \\
(19.14 \% \text { to } 44.72 \%)\end{array}$ \\
\hline & Accuracy & $\begin{array}{l}89.04 \% \\
(79.54 \% \text { to } 95.15 \%)\end{array}$ & $\begin{array}{l}87.67 \% \\
(77.88 \% \text { to } 94.20 \%)\end{array}$ & $\begin{array}{l}72.60 \% \\
(60.91 \% \text { to } 82.39 \%)\end{array}$ \\
\hline
\end{tabular}




\section{DISCUSSION}

Teeth development is a progressive, continuous process that can be followed radiologically. So it is considered a reliable method for age estimation of children and adults in forensic and archaeological contexts (Verma et al. 2011).

The third molar has the advantage of continuous development over a long period and until a later age which makes it one of the predictors for age estimation in the 16-23 years old group (Gandhi et al. 2014).

This study aimed to evaluate the use of Demirjian stages of teeth development in the determination of the age of majority from the left mandibular third molar among a sample of the Egyptian population.

In this study, within the stages of root development D-H, males were ahead than females in stages $\mathrm{D}, \mathrm{F}, \mathrm{G}$ and $\mathrm{H}$, and in all stages we found no statistical difference in the age between sexes.

This result is consistent with is Quintanilla 2010, who stated that many variables were involved in the maturation of individuals, emphasizing the sex-linked genetic trait, as is the advancement in female maturation in relation to males. Though, regarding the lower third molars, there is an advanced development in males, meaning that during adolescence there is an inverse situation between sexes. Also the same finding was observed by Knell et al. 2009 in Swiss and South Europeans, Harris 2007 in American black and whites, and by Orhan et al. 2007 in Turks.

In this study we found a single adult individual in the stage $\mathrm{D}$ and stage $\mathrm{E}$, and 2 individuals in the stage F, while $77.8 \%$ of the males and $86.6 \%$ of the females within stage $\mathrm{G}$ and $97.7 \%$ males and $92 \%$ females within stage $\mathrm{H}$ were adults.

Similarly, Lizarbe et al. 2017 during studying this method among Peruvian population found 2 adult persons in stage $\mathrm{E}$, and 9 persons in the stage F, while $67 \%$ of the males and $87 \%$ of the females within stage $\mathrm{G}$ and $97 \%$ males and $95 \%$ females within stage $\mathrm{H}$ were adults.

On contrary, Treviño 2009, found that for Mexicans from Monterrey, minors corresponded from A to F stages, and he did not found any adult individual in these classification; also adults were those who reached stage $\mathrm{H}$, and $52 \%$ of persons who reached stage $\mathrm{G}$ were adults.

In this study, our results showed that, if the root apices of the third molar are closed (terminal stage $\mathrm{H})$, there is a high probability that the subject is indeed at least 18 years of age ( specificity $90.91 \%$ and $63.64 \%$ for males and females respectively).

However, individuals of adult age whose third molars are at terminal stage $\mathrm{H}$ (sensitivity $84 \%$ for males and $74.19 \%$ for females), and the proportion of correctly classified individuals was $85.25 \%$ for males and $72.60 \%$ for females.

Cameriere et al. 2008 showed a total sensitivity of $58 \%$, specificity of $98 \%$, and accuracy of $79 \%$ for stage $\mathrm{H}$.

Choosing stage $\mathrm{G}$ as an indicator for adult age (sensitivity $98 \%$ for males $95.16 \%$ for females), will increase the sensitivity of the method but decrease the specificity significantly and increases the number of false positive cases. In forensic and medicolegal practice, an adequate test should reduce the number of false positives as much as possible (Martin-de las Heras et al. 2008).

In conclusion, Demirjian's stages $\mathrm{G}$ and $\mathrm{H}$ are fairly accurate and reliable for estimating the age of majority among Egyptians. However, the life of individuals may be significantly affected by the impact of criminal proceedings. It is fundamental to test different parameters and methods to determine whether a person is 18 years and older or younger than 18 (Focardi et al. 2014). Further studies should be performed to test this method on a larger sample, and to test the reliability of other methods in order to establish the most accurate reliable method for estimating the age of majority . 


\section{REFERENCES}

1. Cameriere R, Ferrante L, De Angelis D, Scarpino F, Galli F (2008) The comparison between measurement of open apices of third molars and Demirjian stages to test chronological age of over 18 year olds in living subjects. Int J Legal Med 122:493-7

2. Chan YH (2003): Biostatistics102: Quantitative Data - Parametric \& Non-parametric Tests. Singapore Med J.;44(8): 391-396.

3. Costa J, Montero J, Serrano S, Albaladejo A, LopezValverde A, Bica I. )2014(Accuracy in the legal age estimation according to the third molars mineralization among Mexicans and Columbians. Atencion primaria/ Sociedad Espanola de Medicina de Familia y Comunitaria.; 46 Suppl5:165-75

4. Demirjian A, Goldstein H, Tanner JM (1973) A new system of dental age assessment. Hum Biol 45:211-227 development in relation to chronological age among Turkish children and youth. Forensic Sci Int.165:46-;2007 51.

5. Fletcher R, Fletcher S. Diagnosis. In: Fletcher R, Fletcher $\mathrm{S}$, editors. Clinical epidemiology The essentials. Baltimore: Wolters, Kluwer, Lippincott, Williams \& Wilkins; 2005. p. 35-58.

6. Focardi M, Pinchi V, De Luca F, Norelli GA. Age estimation for forensic purposes in Italy: ethical

7. Galen RS (1980): Predictive values and efficiency of laboratory testing. Pediat J Clin North Am, 27:861-69.

8. Gandhi N , Jain S , Kumar M ., Rupakar P, Choyal K and Prajapati S (2014)Reliability of Third Molar Development for Age Estimation in GujaratPopulation: A Comparative Study

9. Harris EF. Mineralization of the mandibular third molar: a study of American blacks and issues. Int J Leg.

10. Knell B, Ruhstaller P, Prieels F, Schmeling A. Dental age diagnostics by means of radiographical evaluation of the growth stages of lower wisdom teeth. Int J Legal Med. 2009;123:465-9.
11. Lizarbe RJQ, Adrianzén CS, Quezada-Márquez MM, Gali I, Cameriere R (2017) Demirjian's stages and Cameriere's third molarmaturity index to estimate legal adult age in Peruvian population. Legal Med 25:59-65

12. Martin-de las Heras S, Garcia-Fortea P, Ortega A, Zodocovich S, Valenzuela A. Third molar development according to chronological age in populations from Spanish and Magrebian origin. Forensic Sci Int. 2008;174:47-53.

13. Mincer HH, Harris EF, Berryman HE. The A.B.F.O. study of third molar development and its use as an estimator of chronological age. J Forensic Sci. 1993 Mar;38(2):379-90

14. Orhan K, Ozer L, Orhan AI, Dogan S, Paksoy CS. Radiographic evaluation of third molar panorámicas digitales de pacientes del servicio de radiología del C.C.O. de la Universidad de Talcael año 2010. Talca, Chile: Universidad de Talca; 2010.

15. Quintanilla P. Estadio de maduración de terceros molares inferiores en radiografías

16. Schmeling A, Grundmann C, Fuhrmann A, Kaatsch HJ, Knell B, Ramsthaler F et al (2008) Criteria for age estimation in living individuals. Int J Legal Med 122:45760

17. Sharma P., Wadhwan V., Ravi Prakash S.M., Aggarwal P., Sharma N.: (2017) Assessment of age of majority by measurement of open apices of the third molars using Cameriere's third molar maturity index, Journal of forensic dental sciences 9(2) 96-101.

18. terceros molares en una población de 14 a 22 años, en Monterrey (Nuevo León, México) por

19. tomografía computarizada de imágenes. )2009(Granada, Spain: Universidad de Granada; ndhi et al., J Forensic Res 2014, 5:5

20. Treviño M. Estimación de la mayoría de edad por la mineralización y el volumen de los

21. Verma P, Sachdeo J, Gupta VK, Datt GS, Guruprasad R (2011) Age estimation of adolescents and young adults based on development of mandibular third molars: A panoramic study. J Indian Acad Oral Med Radiol 23: 9-13. 